\title{
Verlorener Praxisschlüssel
}

\section{Welcher Versicherer zahlt?}

\author{
Ein verlorener Praxisschlüssel kann teuer werden. Nicht nur, weil schnellstens Schlösser ausgetauscht \\ werden müssen. In der Zwischenzeit könnte auch bereits eingebrochen werden. Dabei sind manche \\ Schlüsselverluste über die Betriebshaftpflicht abgedeckt - aber eben nicht alle.
}

G eht ein Praxisschlüssel verloren, ist der Ärger groß. Da in den Räumen bisweilen teure medizinische Geräte und Computer stehen und zudem noch sensible Patientendaten abgerufen werden könnten, ist es mit der Anfertigung eines Ersatzschlüssels oft nicht getan. Ein Austausch des Schlosses scheint ratsam.

Ob die Versicherung die Kosten dafür übernimmt, hängt unter anderem davon $\mathrm{ab}$, wer den Schlüssel verloren hat. Gut stehen die Chancen, wenn der Arzt es war und die Praxisräume nicht sein Eigentum sind. „Über seine Betriebshaftpflichtversicherung wäre der Schlüsselverlust nur mitversichert, wenn die Praxis gemietet ist", sagt Karl-Heinz Silbernagel, Sprecher der Deutschen Ärzteversicherung.

Denn Haftpflichtpolicen - ob betrieblich oder privat - übernehmen keine Eigenschäden, sondern nur Schäden, die der Versicherte Dritten zufügt. Folglich ist nur der Verlust fremder Schlüssel versichert. „Sollten das Gebäude oder die Praxisräume das Eigentum des Arztes sein, verliert er seine eigenen Schlüssel“, sagt Silbernagel.

\section{MFA nicht immer mitversichert}

Gleiches gilt, wenn der Medizinischen Fachangestellten (MFA) der Schlüssel abhanden kommt: Die Angestellte ist als Erfüllungsgehilfin des Arztes über seine Betriebshaftpflichtpolice nur mitversichert, wenn die Praxis gemietet oder gepachtet ist. „Es ist deshalb wichtig, dass die Medizinische Fachangestellte eine private Haftpflicht hat, die den Verlust gewerblicher Schlüssel abdeckt", so Silbernagel.

Das Dienstschlüsselrisiko ist nicht automatisch Teil der Privathaftpflichtversicherung, kann bei Bedarf aber gegen einen

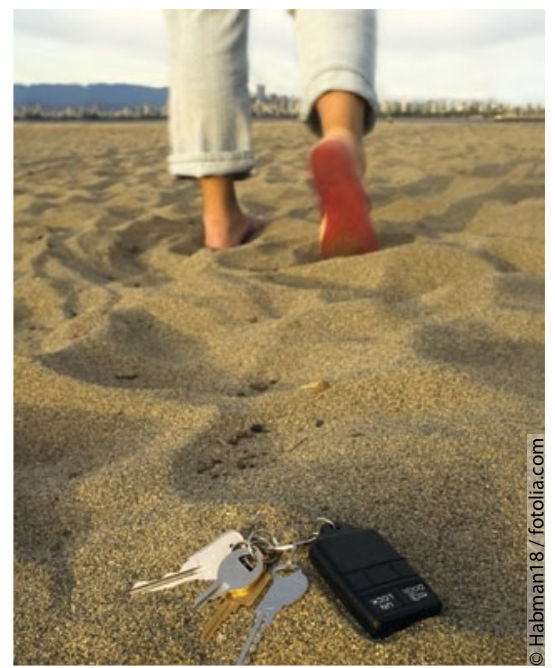

Aufpreis von rund 10 EUR miteingeschlossen werden. Greifen weder Berufs- noch Privathaftpflichtversicherung, bleibt der Mediziner auf den Kosten sitzen. Silbernagel: „Der Arzt kann der Helferin zwar vorwerfen, grob fahrlässig gehandelt zu haben, und Regress fordern, doch das würde in einen langwierigen Prozess münden.“

\section{Die Ehefrau ist ein Spezialfall}

Verliert die Ehefrau des Arztes den Schlüssel, kommt es auf ihre Stellung in der Praxis an. „Ist sie Mitarbeiterin in der Praxis, gilt für sie die gleiche Regelung wie für die Arzthelferin“, sagt er. Hat sie mit der Praxis dagegen nichts zu tun, leistet ihre private Haftpflichtversicherung auch ohne den Dienstschlüsselzusatz. Denn für sie sind es dann keine beruflichen, sondern nur fremde Schlüssel.

Fast genauso ärgerlich wie der Verlust der Praxisschlüssel ist der des Wohnungsoder Hausschlüssels. Beim eigenen Haus oder der Eigentumswohnung hat der Arzt keine Aussichten auf Schadensersatz von seiner Privathaftpflichtversicherung. Es ist ein klassischer Eigenschaden, denn das Schloss gehört ihm selbst. Gleiches gilt, wenn er seinen Autoschlüssel verliert. „Die private Haftpflichtversicherung gilt nur, wenn zur Miete gewohnt wird beziehungsweise wenn für eine Eigentumswohnung zusätzlich ein Schlüssel für den Hauseingang benötigt wird, der der kompletten Hausgemeinschaft gehört und somit ein fremder Schlüssel ist", erläutert Silbernagel.

Besonders der Austausch von Schließanlagen in Mehrfamilienhäusern kann teuer werden. Der Bund der Versicherten (BdV) empfiehlt daher, mindestens eine Deckungssumme von 20.000 EUR zu vereinbaren.

Nicht alle Versicherer betrachten allerdings die Schlüssel zur Mietwohnung als fremden Schlüssel. Bei der Allianz sind etwa Schlüssel zur eigenen Wohnung nicht mitversichert, egal ob der Arzt Mieter oder Eigentümer ist. „Oft machen die Versicherer das an der Frage fest, ob der Mieter die Schlösser austauschen darf “, sagt Hajo Köster vom BdV. Hat der Arzt einen Generalschlüssel, der für Hauseingangs- und Wohnungstür passt, ist das nicht der Fall. Hat er einen separaten Haustürschlüssel, ist ein Austausch dagegen möglich.

Kommt es aufgrund des Schlüsselverlusts zu einem Einbruch, ist das bei der Privatwohnung ein Fall für die Hausratversicherung, bei der Praxis für die Gewerbeversicherung und beim Auto für die Kaskoversicherung. Daher ist es wichtig, beim Schlüsselverlust auch diese Versicherer zu informieren. „Falls der Kunde nicht alle Schlüssel vorweisen kann, zahlt der Versicherer nur einen Teil des Schadens", sagt Christian Lübke, Sprecher des Gesamtverbands der Deutschen Versicherungswirtschaft.

Friederike Krieger 